$06 ; 14$

\title{
Исследование чувствительной способности графена для применений в качестве биосенсоров
}

\author{
() А.С. Усиков ${ }^{1,2}$, С.П. Лебедев ${ }^{3}$, А.Д. Роенков ${ }^{4}$, И.С. Бараш ${ }^{3,4}$, С.В. Новиков ${ }^{5}$, М.В. Пузык ${ }^{6}$, А.В. Зубов ${ }^{2}$, \\ Ю.Н. Макаров ${ }^{1}$, А.А. Лебедев ${ }^{3}$ \\ ${ }^{1}$ Nitride Crystals, Inc., Richmond, USA \\ ${ }^{2}$ Университет ИТМО, Санкт-Петербург, Россия \\ ${ }^{3}$ Физико-технический институт им. А.Ф. Иофффе РАН, Санкт-Петербург, Россия \\ ${ }^{4}$ Группа компаний „Нитридные кристаллы“, Санкт-Петербург, Россия \\ ${ }^{5}$ Aalto University, Espoo, Finland \\ ${ }^{6}$ Российский государственный педагогический университет им. А.И. Герцена, Санкт-Петербург, Россия \\ E-mail: alexander.usikov@nitide-crystals.com
}

Поступило в Редакцию 17 февраля 2020 г.

В окончательной редакции 17 февраля 2020 г.

Принято к публикации 18 февраля 2020 г.

Исследована реакция чипов на основе пленок графена на подложках $\mathrm{SiC}$ (относительное изменение сопротивления чипа) на их контакт с флуоресцеином $\left(\mathrm{C}_{20} \mathrm{H}_{12} \mathrm{O}_{5}\right)$ в широком диапазоне его концентраций в фосфатно-солевом буферном растворе: от $1 \cdot 10^{-3}$ до $1 \cdot 10^{4} \mathrm{ng} / \mathrm{ml}$ (семь порядков). Детектирование флуоресцеина представляется простым и дешевым модельным экспериментом для исследования сенсорной способности графена на пути изготовления биочипов. Показано, что чипы с широкими террасами на поверхности с шириной ступеней около $1000 \mathrm{~nm}$ и их высотой до $5 \mathrm{~nm}$ позволили построить калибровочные зависимости реакции чипов от концентрации флуоресцеина.

Ключевые слова: графен, карбид кремния, биосенсор, флуоресцеин.

DOI: 10.21883/PJTF.2020.10.49421.18250

Двумерная гексагональная упаковка атомов углерода в графене в форме одного или нескольких монослоев обладает уникальными свойствами [1], что способствует разработкам по созданию различных типов электронных приборов [2], а также био- и газовых сенсоров $[3,4]$. Отличительной особенностью пленки графена является то, что адсорбируемые на ее поверхность молекулы или группа атомов действуют как донор или акцептор, приводя к изменению ее электронного состояния (сопротивления), которое можно зарегистрировать. Это изменение сопротивления графенового канала между двумя контактами в чипе может быть зарегистрировано современными электронными приборами. Такая специфика пленки графена может быть использована при создании биосенсоров для регистрации (диагностики) предельно низких концентраций биомолекул, связанных с различными социально значимыми заболеваниями (гепатит, онкология, ВИЧ или гемолиз) на ранней стадии.

Для разработки физических методов моделирования взаимодействия лекарственных препаратов с белковыми структурами (например, сывороточный альбумин человека) в качестве тест-объекта часто используется флуоресцеин или его производные [5]. В связи с этим представляет интерес проведение исследований по детектированию низких концентраций флуоресцеина $\left(\mathrm{C}_{20} \mathrm{H}_{12} \mathrm{O}_{5}\right)$ для моделирования работы сенсоров белковых структур (биосенсоров) на основе пленок графена. В работе проводилась серия экспериментов с подготовленными чипами на основе пленок графена на подложках из карбида кремния ( $\mathrm{SiC})$ по исследованию их чувствительности (реакции) при контакте с разбавленными растворами флуоресцеина, концентрация которого изменялась на семь порядков, начиная со сверхнизкой величины $1 \mathrm{ng} / \mathrm{l}$ $\left(10^{-3} \mathrm{ng} / \mathrm{ml}\right)$, в фосфатно-солевом буферном растворе (PBS). В качестве реакции графена на флуоресцеин исследовалось относительное изменение сопротивления графенового чипа до и после его контакта с раствором флуоресцеина.

Графеновые пленки были получены путем термического разложения полуизолирующих подложек $(0001) \pm 0.25^{\circ} 4 H$-SiC размером $11 \times 11 \mathrm{~mm}$. Процесс выращивания проводился в графитовом тигле с индукционным нагревом в атмосфере аргона (720-750 Torr) при температуре $1700-1800^{\circ} \mathrm{C}$ [6]. Присутствие монослоя графена на подложке $\mathrm{SiC}$ подтверждалось по спектрам комбинационного рассеяния света [6]. Топология чипов прямоугольной формы на поверхности пластинки графен/SiC формировалась методом лазерной фотолитографии в сочетании с ионно-реактивным травлением в аргоне и травлением в кислородной плазме. Контакты $\mathrm{Ti} / \mathrm{Au}(5 \mathrm{~nm} / 50 \mathrm{~nm})$ создавались вакуумным напылением и взрывной фотолитографией. После процессирования пластинка графен/SiC разрезалась на отдельные чипы размером $1.5 \times 2 \mathrm{~mm}$, которые монтировали на держателе из текстолита, разваривая золотыми проводками. Затем все токоведущие части держателя и контактные площадки чипа покрывались защитным лаком. Сенсорная площадь поверхности графена в чипе была $1 \times 1.5 \mathrm{~mm}$. 

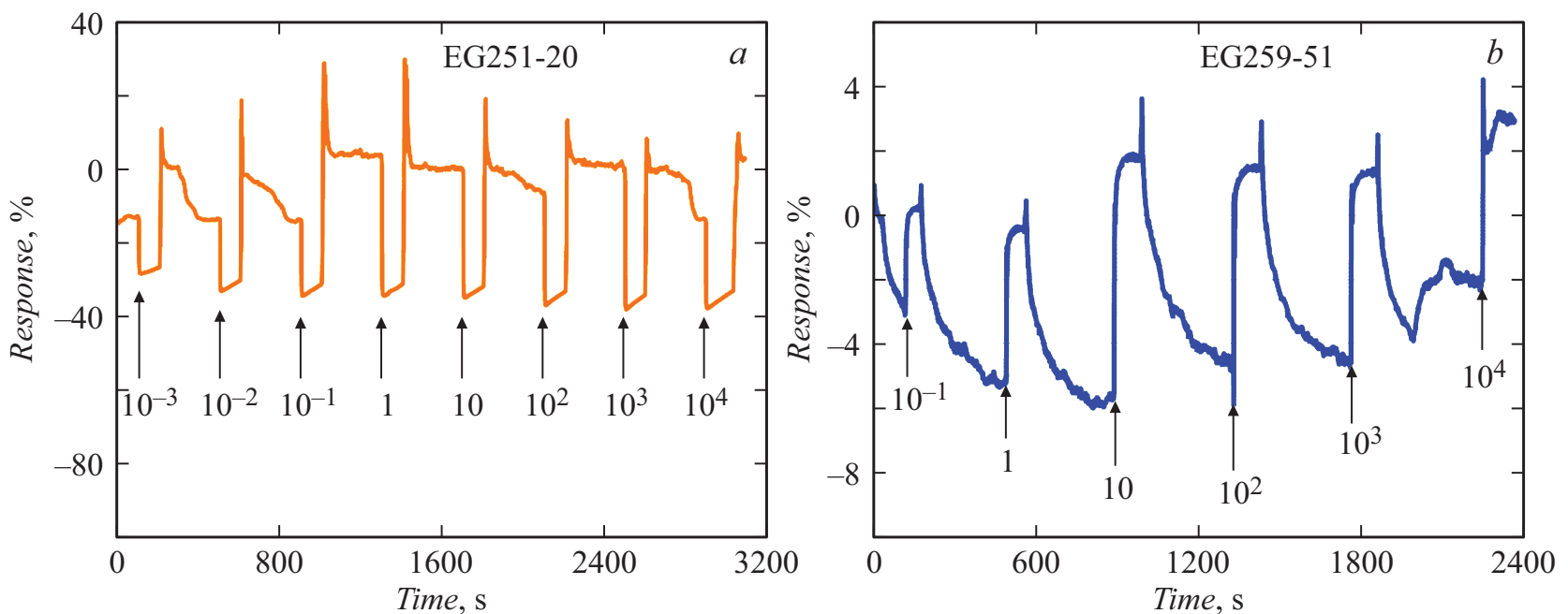

Рис. 1. Реакция чипов на их последовательный контакт с растворами флуоресцеина разной концентрации. Стрелки показывают моменты времени опускания чипа в растворы с флуоресцеином. Числа под стрелками - концентрация флуоресцеина в растворе (в $\mathrm{ng} / \mathrm{ml}) . a$ - образец серии ЕG251, $b$ - образец серии EG259.

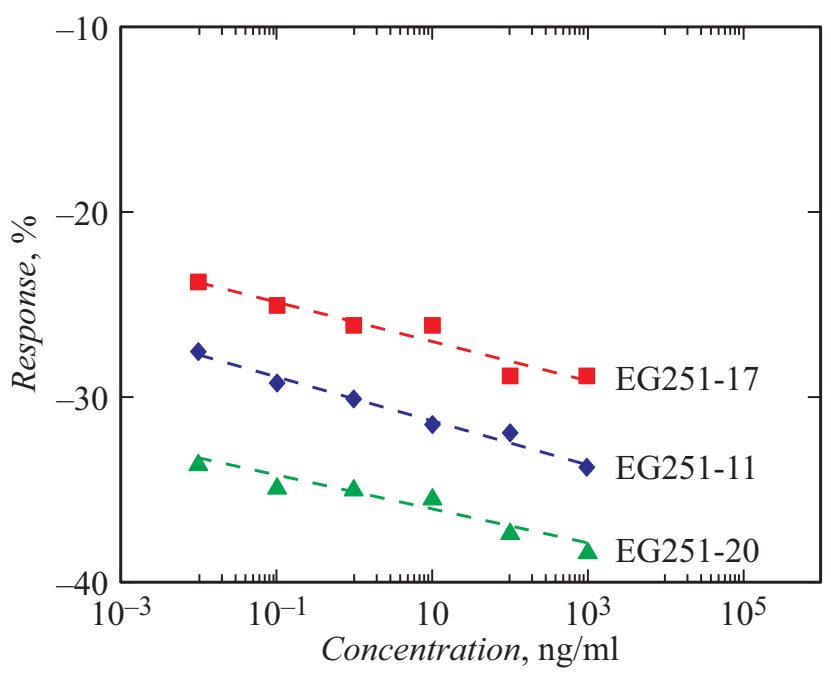

Рис. 2. Реакция чипов серии EG251 в зависимости от концентрации флуоресцеина. Данные получены из серии экспериментов с несколькими чипами, реакция которых на флуоресцеин была подобна изображенной на рис. $1, a$. Штриховые линии показывают логарифмическую аппроксимацию результатов со среднеквадратичным отклонением 0.92-0.98.

Вольт-амперные характеристики изготовленных чипов были линейными, что свидетельствовало об омических контактах и об отсутствии потенциальных барьеров на контактах, которые могут повлиять на результаты измерений.

Сама по себе пленка графена не является селективночувствительным сенсором и может присоединять к своей поверхности разные вещества и биомолекулы. Для использования графена в качестве биосенсора применяется функционализация (обработка) его поверхности [7,8]. Такая обработка изменяет химические реакции на поверх- ности графена (повышает избирательность химических реакций) и создает дополнительные ковалентные связи для химических реакций с другими молекулами. В настоящей работе процесс функционализации поверхности графена в чипе осуществлялся в два этапа путем создания ковалентных связей при нанесении нитрофениловых групп (нитробензол, $\mathrm{C}_{6} \mathrm{H}_{5} \mathrm{NO}_{2}$ ) и их последующего восстановления до фениламинных групп (аминобензол, $\left.\mathrm{C}_{6} \mathrm{H}_{5} \mathrm{NH}_{2}\right)$ с применением метода циклической вольтамперометрии [7]. Процесс функционализации графена описан авторами в деталях в работе [9].

Затем функционализованная поверхность графена покрывалась антителом, которое химически взаимодействует именно с флуоресцеином. В экспериментах в качестве антитела, специфичного к флуоресцеину, использовалось F-2A3 с исходной концентрацией $50 \mu \mathrm{g} / \mathrm{ml}$ в PBS. Раствор гомогенизировался в ультразвуковой ванне в течение $30 \mathrm{~min}$. Графеновые чипы помещали в приготовленный раствор на $3 \mathrm{~h}$, после чего их вынимали и промывали в PBS. Подготовленные таким образом чипы использовались для теста на реакцию с флуоресцеином.

Детектирование флуоресцеина в настоящей работе основано на химической реакции соединения антигена с комплементарным ему антителом, при которой происходит изменение сопротивления графенового канала, которое тут же фиксируется по изменению протекающего тока при подаче стабилизированного напряжения $60 \mathrm{mV}$ на чип. В качестве реакции чипа $r$ (response) определялось относительное изменение сопротивления чипа $R$ со временем при подаче стабилизированного напряжения: $r=\left(R-R_{0}\right) / R_{0}$, где $R_{0}-$ начальное сопротивление чипа.

Для осуществления реакции на флуоресцеин чипы на держателе погружались в PBS c флуоресцеином 
$a$

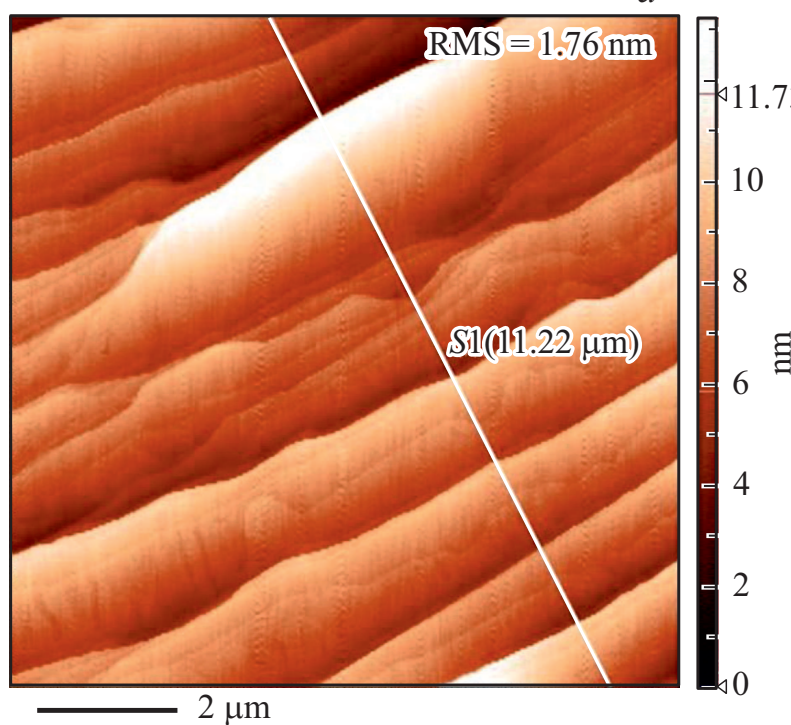

$b$

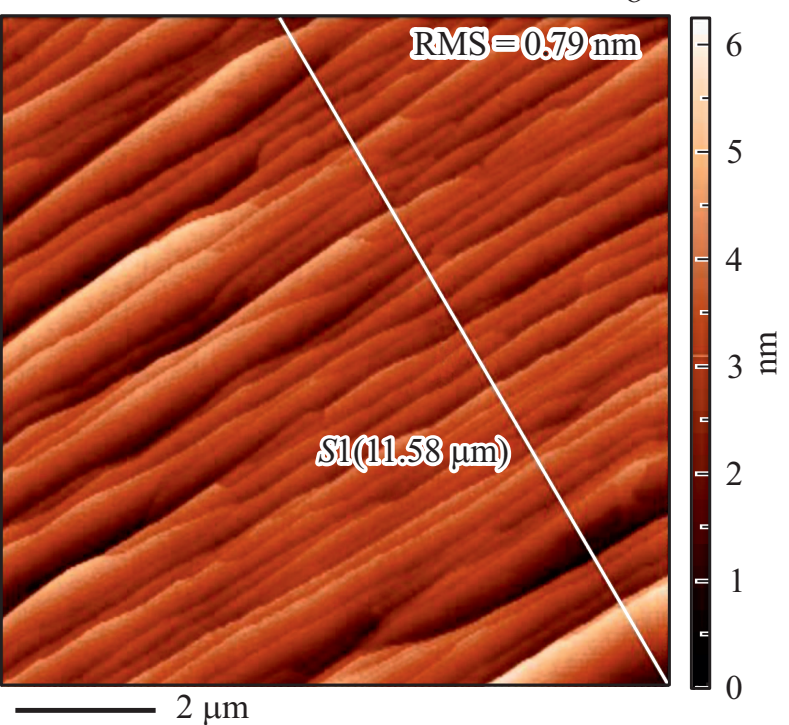

Рис. 3. АСМ-топография поверхности подложки $\mathrm{SiC}$ после роста графена (поле сканирования $10 \times 10 \mu \mathrm{m}$ ). $a-$ образец $\mathrm{EG} 251$, $b$ - образец ЕG259.

на 1-2 min. Затем вынимались обратно, высушивались в потоке аргона в течение 3-4 min и снова опускались в другой раствор с другой концентрацией флуоресцеина. В некоторых экспериментах раствор наносился каплями на поверхность чипа. Концентрация флуоресцеина в используемых растворах была следующей: $10^{-3}, 10^{-2}$, $10^{-1}, 1,10,10^{2}, 10^{3}$ и $10^{4} \mathrm{ng} / \mathrm{ml}$. Каждый раствор гомогенизировался в ультразвуковой ванне. После каждого измерения чип высушивался в атмосфере аргона.

Реакция чипов во времени на их последовательный контакт с различной концентрацией флуоресцеина в PBS показана на рис 1. Чип из серии EG251 (рис. 1,a) показал реакцию в виде хорошо различимых прямоугольных пиков (импульсов). Ширина пиков соответствует времени контакта чипа с раствором флуоресцеина $(100-120 \mathrm{~s})$, а их величина зависит от концентрации флуоресцеина в растворе. В проведенной серии экспериментов чипы этой серии демонстрировали аналогичную изображенной на рис. $1, a$ реакцию, когда они окунались в раствор с флуоресцеином или когда на область подготовленного графена в чипе наносилась капля раствора. Однако реакция чипов другой серии (EG259) имела иной характер и была не столь очевидной и воспроизводимой (рис. $1, b$ ). На рисунке в качестве примера показана реакция только одного чипа серии EG259. Данные, приведенные на рис. 1, $a$, и подобные им для других чипов серии EG251 позволили построить калибровочные зависимости реакции чипов от концентрации флуоресцеина, которые представлены на рис. 2. Заметим, что для больших концентраций $\left(10^{4} \mathrm{ng} / \mathrm{ml}\right.$, рис. $\left.1, a, b\right)$ происходило насыщение реакции чипов. Реакция же чипов в сильно разбавленном растворе $\left(10^{-3} \mathrm{ng} / \mathrm{ml}\right)$ была заметно слабее. Поэтому эти крайние точки концентраций не указаны на рис. 2.
Реакции чипов в зависимости от концентрации флуоресцеина хорошо аппроксимировались логарифмической зависимостью. Подобная зависимость наблюдалась ранее при исследовании реакции биосенсора на основе графена на контакт с растворами альбумина яичного белка в PBS [10].

Особенности реакции различных чипов на рис. 1 могут быть связаны с различием в морфологии поверхности используемых образцов. После роста графена поверхность $\mathrm{SiC}$ представляет собой набор атомно-гладких террас, разделенных ступенями. На рис. 3 представлены изображения поверхности чипов EG251 и EG259, полученные при помощи атомно-силового микроскопа (ACM). Поверхность образца EG251 покрыта широкими террасами $(1-2 \mu \mathrm{m})$, разделенными ступенями высотой 5-8 nm. На поверхности образцов серии EG259 преобладают узкие террасы $(300-500 \mu \mathrm{m})$, разделенные ступенями высотой $0.5-2 \mathrm{~nm}$.

По-видимому, присоединение большой и тяжелой молекулы флуоресцеина (молярная масса $332.3 \mathrm{~g} / \mathrm{mol}$ ) к функционализированному графену с антителом на поверхности осуществляется более эффективно и прочно при наличии широких ступеней (рис. 3,a). Такая морфология поверхности лучше согласуется с размерами молекулы флуоресцеина, которая представляет собой сплющенный эллипсоид с характерными размерами полуосей 0.7 и $0.2 \mathrm{~nm}$ [11]. Можно предположить также, что из-за геометрического фактора поверхности графена количество антител флуоресцеина больше на широких террасах, и поэтому общий отклик (реакция) для таких чипов выражен более явно. Кроме того, важно, чтобы антитела находились как можно ближе к графену, чтобы изменение заряда при реакции присоединения 
флуоресцеина передавалось на графен. По-видимому, для широких террас это условие выполняется лучше.

Выращенные пленки графена имели $n$-тип проводимости. Уменьшение реакции чипов (т. е. уменьшение сопротивления) серии EG251 может означать, что присоединение молекулы флуоресцеина создает донороподобный эффект в пленке графена, дающий дополнительные носители (электроны). Реакция же чипа EG259-51 на рис. 1, $b$ показывает увеличение сопротивления графенового чипа. По-видимому, здесь можно говорить об эффекте разной пространственной ориентации большой по размеру молекулы флуоресцеина при присоединении к разным по размеру террасам на графеновой пленке. Однако не исключено, что двухслойный графен, который по измерениям частично покрывает образцы, тоже влияет на пространственную ориентацию молекулы флуоресцеина на поверхности графена. Дальнейшие исследования необходимы для выяснения влияния фактора морфологии поверхности пленки графена на подложках $\mathrm{SiC}$ на механизм детектирования флуоресцеина и белковых соединений.

Таким образом, проведено исследование реакции чипов (относительное изменение сопротивления чипа) на основе пленок графена на подложках $\mathrm{SiC}$ на флуоресцеин в диапазоне концентраций флуоресцеина в фосфатно-солевом буферном растворе, охватывающем семь порядков величины (от $10^{-3}$ до $10^{4} \mathrm{ng} / \mathrm{ml}$ ). Экспериментальные зависимости реакции чипов с шириной ступеней на поверхности около $1000 \mathrm{~nm}$ и их высотой $5 \mathrm{~nm}$ (чипы серии EG251) от концентрации флуоресцеина полностью аппроксимировались логарифмической зависимостью. Предполагается, что геометрический фактор морфологии поверхности и специфика пространственной ориентации больших по размерам молекул флуоресцеина влияют на реакцию чипов при их контакте с флуоресцеином.

\section{Благодарности}

Авторы благодарят П.А. Дементьева за АСМизмерения.

\section{Конфликт интересов}

Авторы заявляют, что у них нет конфликта интересов.

\section{Список литературы}

[1] Novoselov K.S., Geim A.K., Morozov S.V., Jiang D., Zhang Y., Dubonos S.V., Grigorieva I.V., Firsov A.A. // Science. 2004. V. 306. P. $666-669$.

[2] Wu Y., Lin Y.-M., Bol A.A., Jenkins K.A., Xia F., Farmer D.B., Zhu Y., Avouris P. // Nature. 2011. V. 472. P. 74-78.

[3] Schedin F., Geim A.K., Morozov S.V., Hill E.W., Blake P., Katsnelson M.I., Novoselov K.S. // Nature Mater. 2007. V. 6. P. 652-655.
[4] Лебедев А.А., Давыдов В.Ю., Новиков С.Н., Литвин Д.П., Макаров Ю.Н., Климович В.Б., Самойлович М.П. // Письма в ЖТФ. 2016. Т. 42. В. 14. С. 28-35. [Пер. версия: 10.1134/S1063785016070233].

[5] Vlasova I.M., Saletsky A.M. Current Appl. Phys. 2009. V. 9. P. $1027-1031$.

[6] Давыдов В.Ю., Усачёв Д.Ю., Лебедев С.П., Смирнов А.Н., Левицкий В.С., Елисеев И.А., Алексеев П.А., Дунаевский М.С., Вилков О.Ю., Рыбкин А.Г., Лебедев А.А. // ФТП. 2017. T. 51. B. 8. C. $1116-1124$.

DOI: 10.21883/FTP.2017.08.44800.8559 [Пер. версия: 10.1134/S1063782617080073].

[7] Georgakilas V., Otyepka M., Bourlinos A.B., Chandra V., Kim N., Kemp K.C., Hobza P., Zboril R., Kim K.S. // Chem. Rev. 2012. V. 112. P. 6156-6214.

[8] Tehrani Z., Burwell G., Mohd Azmi M.A., Castaing A., Rickman R., Almarashi J., Dunstan P., Miran Beigi A., Doak S.H., Guy O.J. // 2D Mater. 2014. V. 1. P. 025004 (1-19).

[9] Usikov A., Borodkin K., Novikov S., Roenkov A., Goryachkin A., Puzyk M., Barash I., Lebedev S., Zubov A., Makarov Y., Lebedev A. // Proc. of the Estonian Academy of Sciences. 2019. V. 68. P. 207-213. DOI: $10.3176 /$ proc. 2019.2 .13

[10] Eissa S., Contreras Jimenez G., Mahvash F., Guermoune A., Tlili C., Szkopek T., Zourob M., Siaj M. // Nano Res. 2015. V. 8. P. 1698-1709. DOI: 10.1007/s12274-014-0671-0

[11] Pu Y., Wang W., Dorshow R.B., Alfano R.R. // Proc. of SPIE. V. 8258. P. 825818 (1-5). DOI: $10.1117 / 12.904692$ 